\title{
ЦИТ: ua117-048
}

DOI: $10.21893 / 2415-7538.2016-06-5-048$

УДК 577.342:53.08

\section{1 Гуцул О.В., ${ }^{2}$ Слободян В.3. ВПЛИВ ФЕРИТУ І КОРОТКО ЗАМКНУТИХ ВИТКІВ НА ЧАСТОТНІ ЗАЛЕЖНОСТІ ДОБРОТНОСТІ КОЛИВАЛЬНОГО КОНТУРУ}

${ }^{1}$ ВДНЗУ «Буковинський державний медичний університет», Чернівиі, Театральна пл. 2, 58002

${ }^{2}$ Чернівецьький національний університет ім. Юрія Федьковича, Чернівиі, Коиюбинського 2, 58012

${ }^{1}$ Hutsul O. V., ${ }^{2}$ Slobodyan V.Z.

IMPACT OF FERRITE AND BRIEFLY CLOSED TURNS ON THE FREQUENCY DEPENDENCE OF THE Q-FACTOR OF OSCILLATOR CIRCUIT

Bukovinian State Medical University, Chernivtsi, Theatralna sq. 2, 58002

Yuriy Fedkovych Chernivtsi National University, Kotsjubynskyi Str. 2, Chernivtsi 58012

Анотація. У роботі розглянуто вплив фериту і коротко замкнутих витків на частотні залежності добротності коливального контуру. Одержано графічні залежності добротності від резонансної частоти коливального контуру у випадку: 1 - відсутності фериту $i$ коротко замкнутих витків; 2 наявності лише фериту; 3 - наявності лише коротко замкнутих витків; 4 наявності як фериту, так $i$ коротко замкнутих витків. Розраховано індуктивності контуру та побудовано графічні залежсності активного опору коливального контуру для цих випадків. Розглянуто теоретичні формули для пояснення експериментальних частотних залежностей добротності. Пояснено вплив коротко замкнутих витків на частотні залежності добротності викликані скін-ефектом в металі.

Ключові слова: добротність, коливальний контур, скін-ефект, частотні залежності.

Abstract. In this paper we described the impact and briefly closed ferrite coils depending on the frequency oscillator circuit Q-factor. Depending obtained image $Q$ - factor of the resonant frequency of an oscillator circuit in case of: 1 - no ferrite coils and briefly closed; 2 - there is only ferrite; 3 - there is only closed briefly turns; 4 - available as ferrite and briefly closed turns. Calculated inductor circuit and built graphics depending on the active resistance oscillator circuit for these cases. We described the theoretical formula for explaining the experimental frequency dependence of Q-factor. Closed briefly explained the impact of revolutions on the frequency dependence of $Q$-factor due to the skin effect in the metal.

Key words: Q-factor, resonant circuit, skin effect, frequency dependence.

Вступ.

Добротність $Q$ коливального контуру характеризує процеси, які відбуваються як в самому контурі, так i за його межами, завдяки 
електромагнітній індукції в середовищі із різним типом електропровідності. Для ідентифікації різних типів процесів, що відбуваються в коливальному контурі неоціненний вклад дають недостатньо вивченні частотні залежності добротності $[1,2]$.

Дослідження проводилось на установці (рис.1).

Частотні залежності добротності коливального контуру для різних комбінацій фериту і коротко замкнутих витків (рис.2) при відсутності фериту та коротко замкнутих витків $\left(Q_{1}\right)$, при наявності лише фериту $\left(Q_{2}\right)$, при наявності лише коротко замкнутих витків $\left(Q_{3}\right)$ та при наявності і фериту i коротко замкнутих витків $\left(Q_{4}\right)$.

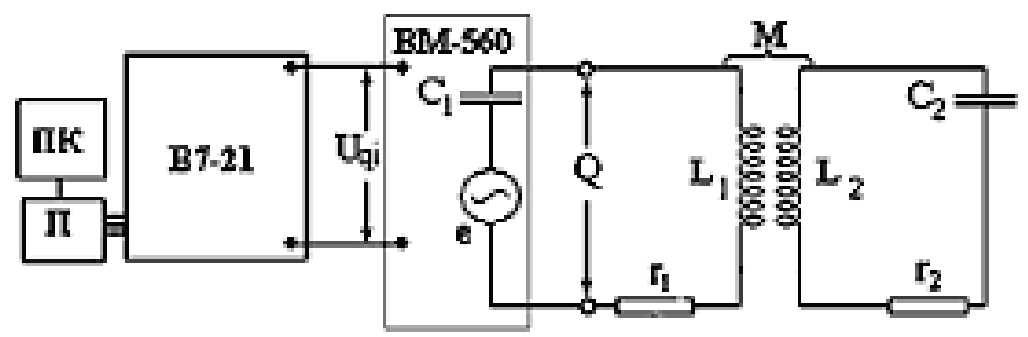

a)

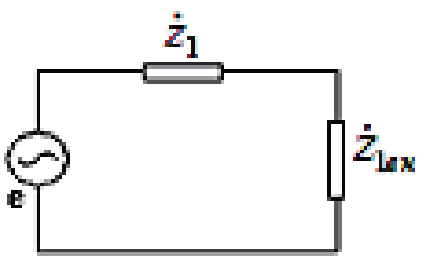

б)

Рис.1. Схема установки для експериментальних досліджень частотних залежностей добротності $Q$ коливального контуру $L_{1} C_{1}$ (a) та приведена розрахункова схема (б).

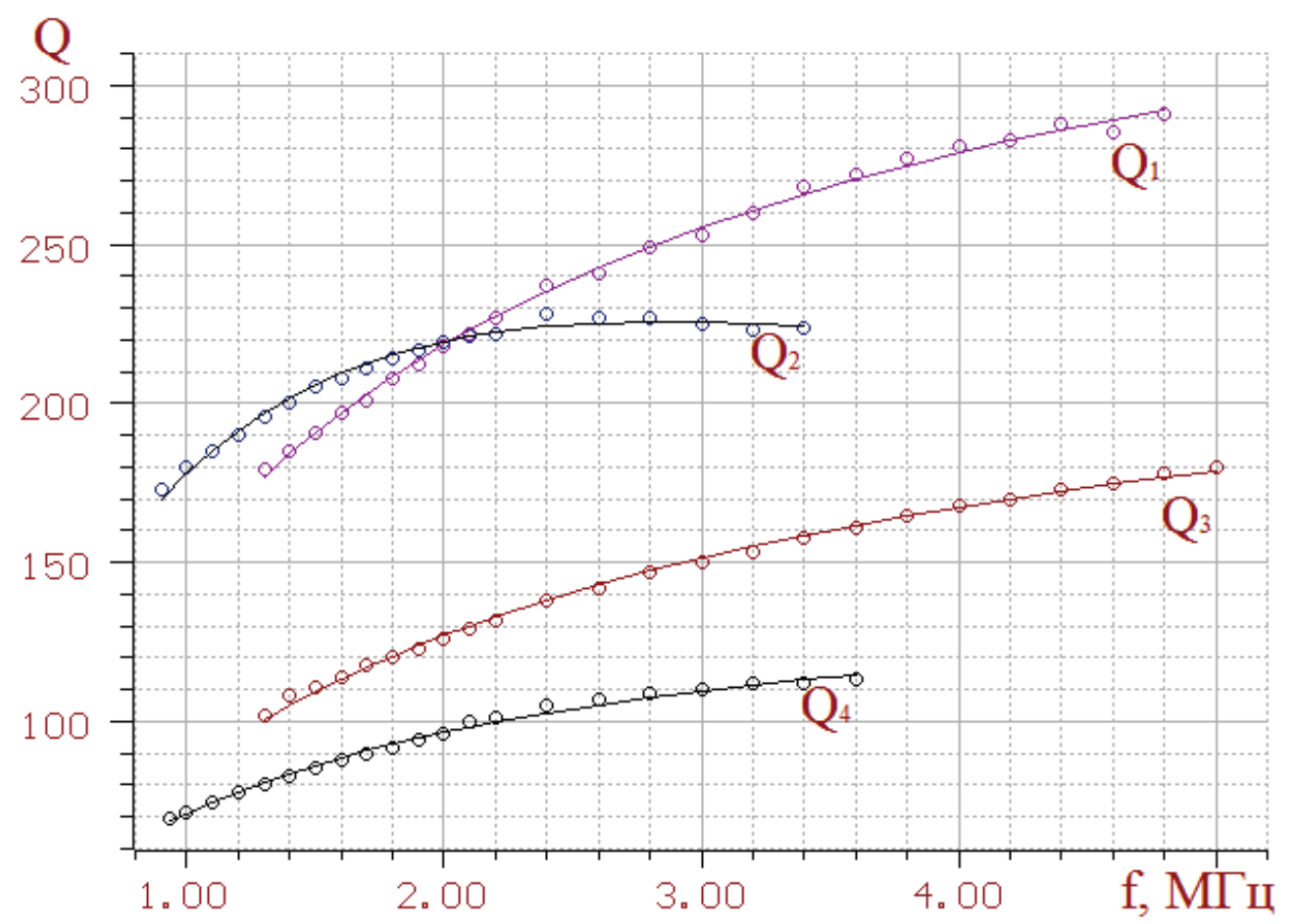

Рис.2. Частотні залежності добротності $Q$ коливального контуру для чотирьох випадків.

Використання набору експериментальних значень ємності та частоти дозволило розрахувати індуктивності $L$ коливального контуру для 
вищезгаданих чотирьох випадків: $L_{1}=38.25 \mathrm{\mu \kappa} \Gamma \mathrm{H}, \quad L_{2}=77.82 \mathrm{m \kappa} \Gamma \mathrm{H}$, $L_{3}=34.48 \mathcal{M} \Gamma \mu$ і $L_{4}=63.57 \mathcal{M} \Gamma \mu$. Враховуючи, що добротність коливального контуру визначається формулою:

$$
Q=\omega L / R
$$

нами було побудовано залежності активного опору для розглянутих випадків при відсутності фериту і коротко замкнутих витків $\left(R_{1}\right)$, при наявності лише фериту $\left(R_{2}\right)$, при наявності лише коротко замкнутих витків $\left(R_{3}\right)$ та при наявності і фериту і коротко замкнутих витків $\left(R_{4}\right)$ (рис.3).

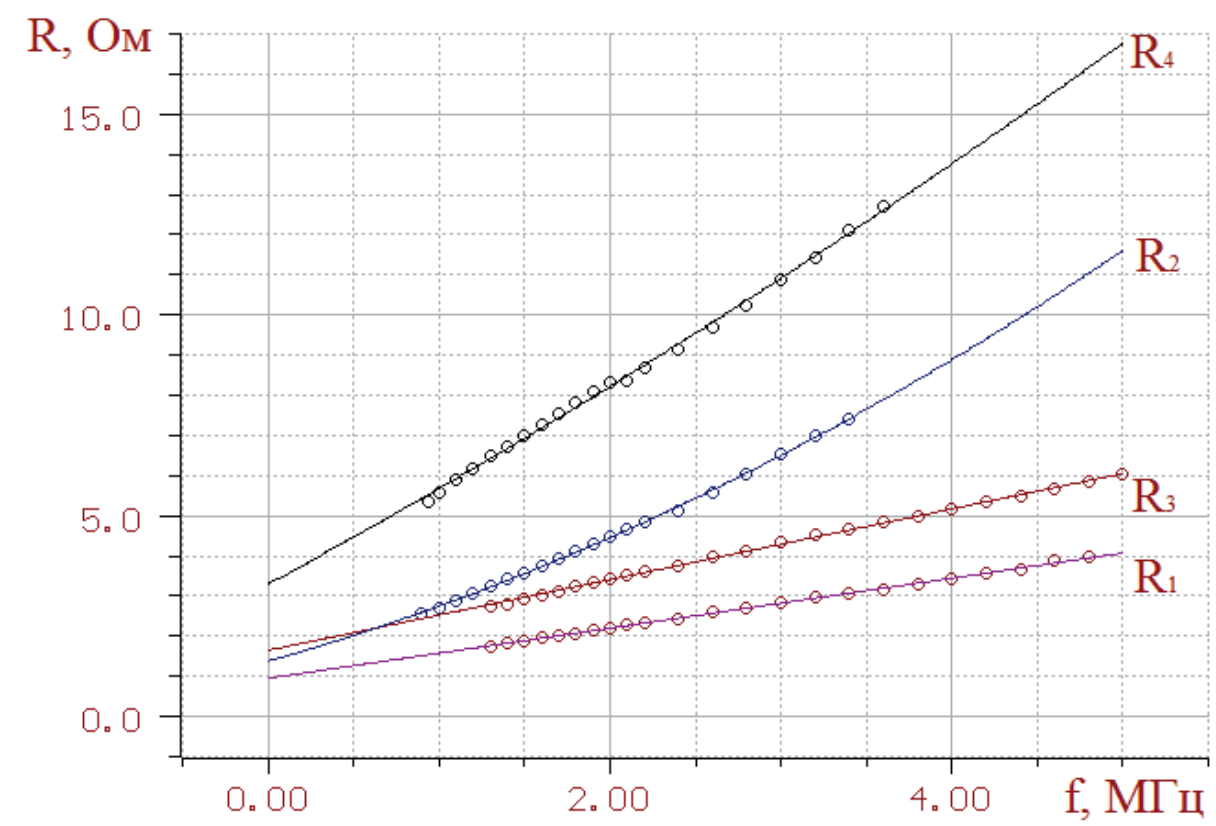

\section{Рис.3. Частотні залежності активного опору коливального контуру для чотирьох випадків.}

Використовуючи експериментальні дані для трьох перших опорів було теоретично розраховано частотну залежність $R_{4}(f)$ по формулах:

$$
\begin{gathered}
R_{4}=R_{1}+\left(R_{2}-R_{1}\right)+\left(R_{3}-R_{1}\right) ; \\
R_{4}=R_{1}+\left(\left(L_{4} / L_{3}\right)^{2}\right)\left(R_{3}-R_{1}\right)+\left(\left(L_{4} / L_{2}\right)^{2}\right)\left(R_{2}-R_{1}\right) ; \\
R_{4}=R_{1}+\left(\left(L_{4} / L_{3}\right)^{2}\right)\left(R_{3}-R_{1}\right)+\left(L_{4} / L_{2}\right)\left(R_{2}-R_{1}\right) ; \\
R_{4}=R_{1}+\left(L_{4} / L_{3}\right)\left(L_{2} / L_{3}\right)\left(R_{3}-R_{1}\right)+\left(\left(L_{4} / L_{2}\right)^{2}\right)\left(R_{2}-R_{1}\right) ; \\
R_{4}=R_{1}+\left(L_{4} / L_{3}\right)\left(L_{2} / L_{3}\right)\left(R_{3}-R_{1}\right)+\left(L_{4} / L_{2}\right)\left(R_{2}-R_{1}\right) .
\end{gathered}
$$

Результати розрахунків показують (рис.4), що формула (4) найкраще описує експериментальні дані, оскільки коректно враховує зміну коефіцієнтів взаємоіндукції, викликаних як зміною індуктивності первинної обмотки (ферит i коротко замкнуті витки) так і зміною індуктивності замкнутих струмів Фуко (ферит).

Слід відмітити, що частотні залежності додаткового активного опору, викликані наявністю коротко замкнутих витків теоретично пояснюються частотною залежністю скін-ефекту металу із якого виготовлені коротко замкнуті витки (рис.5). 


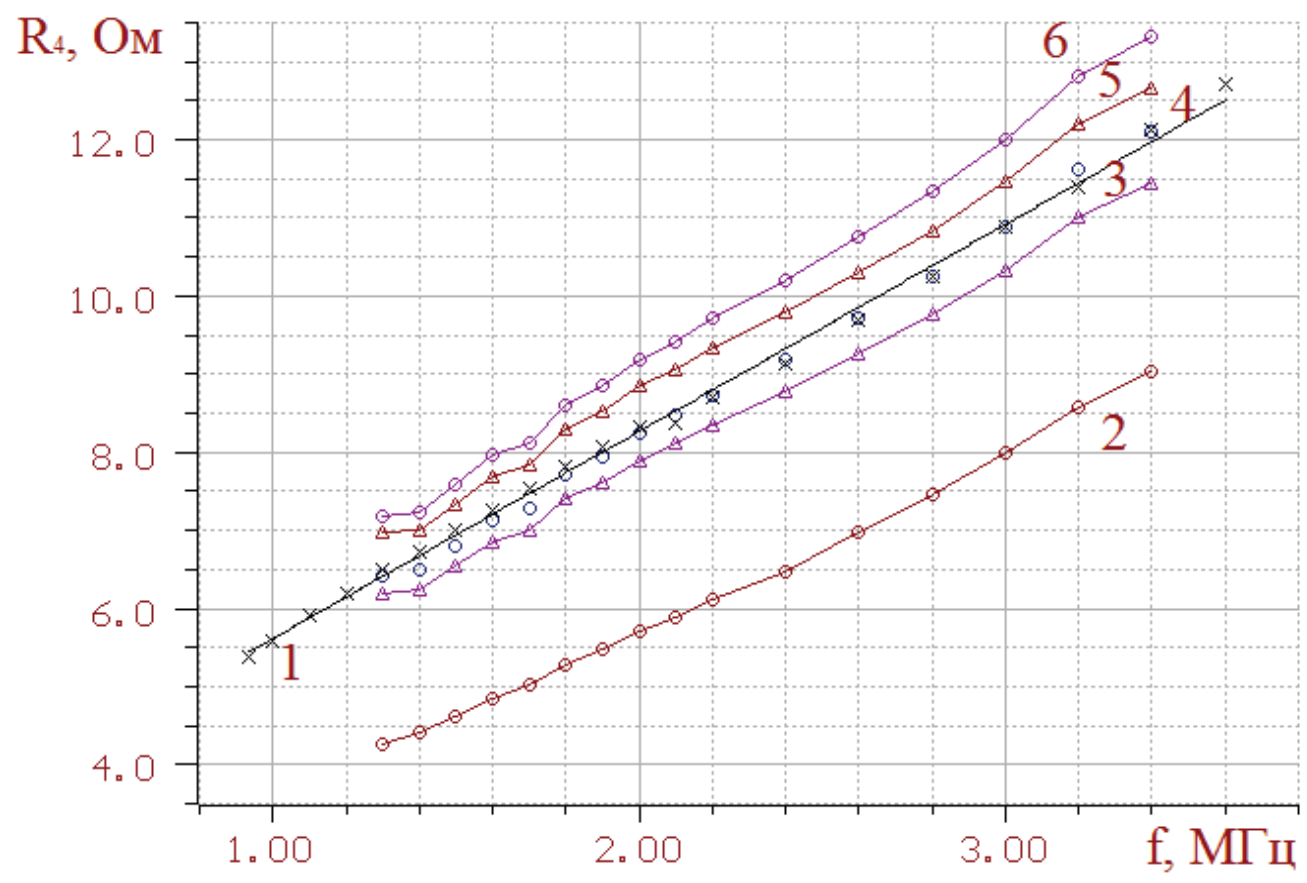

Рис.4. Порівняння експериментальної (1) і теоретичних (2-6) частотних залежностей активного опору, розрахованих по формулам (2-6).

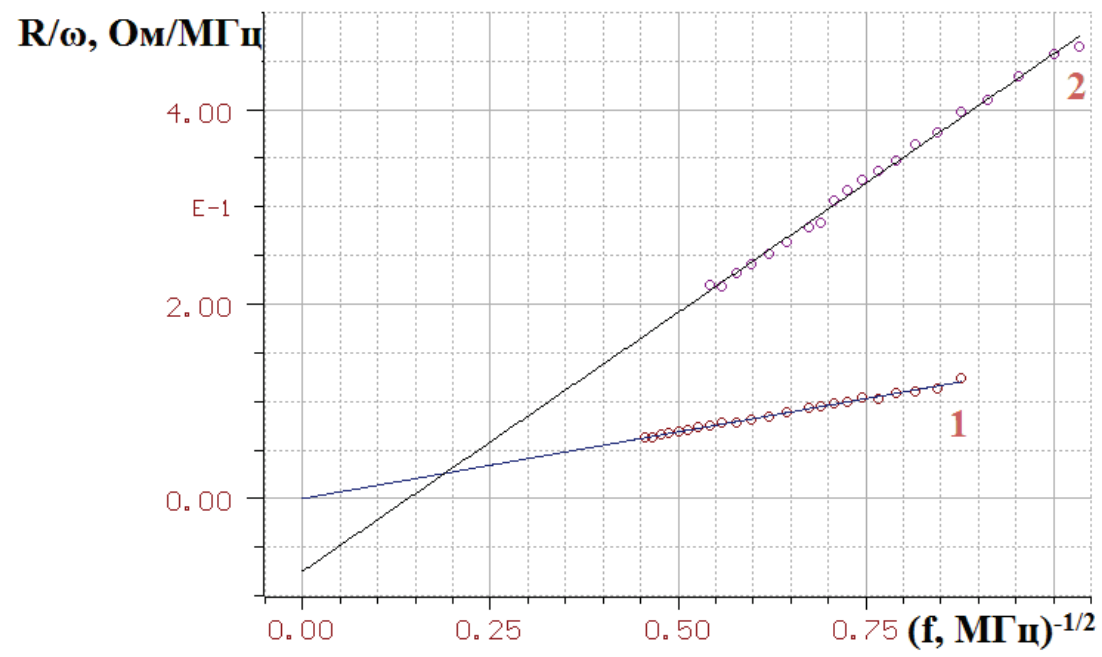

Рис.5. Частотні залежності відношення додаткового активного опору до циклічної частоти викликаного наявністю коротко замкнутих витків у коливальному контурі: без фериту (1) і при наявності фериту (2).

\section{Заключення і висновки.}

Було отримано адитивну формулу (2), яку можна використовувати лише при незначних змінах індуктивності коливального контуру, що значно спрощує розрахунки. Було показано, що використання фериту змінює величину скінефекту завдяки магнітній проникливості, залишаючи незмінною частотну залежність.

Література:

1. Гуцул О. В. Дослідження частотної залежності скін-ефекту для провідників І-го та II-го роду / О. В. Гуцул, В. 3. Слободян. // Zbior artykulow 
naukowych. Konferencji Miedzynarodowej Naukowo-Praktycznej "Inzynieria i technologia. Teoretyczne i praktyczne aspekty rozwoju wspolczesnej nauki" (30.03.2017-31.03.2017) - Warszawa: Wydawca: Sp. z o.o. "Diamond trading tour. 2017. - C. 42-46.

2. Gutsul O. V. Skin-effect of fluid in capillaries / O. V. Gutsul, V. Z. Slobodian. // SWorld Journal. - 2016. - №11, vol. 10 - C. 44-47.

Статья отправлена: 5.06.2017 г.

(C) Гуцул О.В., Слободян В.3.

\section{ЦИТ: иа117-082}

DOI: 10.21893/2415-7538.2016-06-5-082

УДК 517.9

\section{ОПТИМАЛЬНЫЙ УГОЛ БРОСАНИЯ ТЕЛ \\ В ПОЛЕ ТЯЖЕСТИ ЗЕМЛИ С УЧЕТОМ ЕЕ ВРАЩЕНИЯ}

Окулов С.А., Демина Е.Л.

Уральский федеральный университет,

Нижнетагильский технологический институт (филиал),

г. Нижний Тагил, Свердловская область

Okulov S.A., Demina E.L.

\section{OPTIMUM ANGEL BODY TOSSING IN THE EARTH GRAVITY} FIELD CONSIDERING ITS ROTATION

Ural Federal University, Nizhny Tagil Technological Institute (branch), Nizhny Tagil, Sverdlovskaya Region

Аннотачия: В работе операчионным методом получено точное решение задачи о влиянии вращения Земли на движение тела при ненулевых начальных условиях. Исследовано влияние вращения Земли на оптимальный угол бросания.

Ключевые слова: Движение в поле тяжести; уравнения движения; оптимальный угол бросания.

Abstract. In this paper by operation method the exact solution of a task about influence of the Earth rotation is received on body movement upon non-zero initial conditions. There has been studied the Earth rotation impact on the optimum angle tossing.

Key words : Motion in a gravitational field; equations of motion; optimal angle tossing.

Изучим влияние вращения Земли на движение тел в поле ее тяжести, задаваемого следующей системой дифференциальных уравнений [1]:

$$
\left\{\begin{array} { l } 
{ \ddot { x } = 2 \omega ( \dot { z } \operatorname { c o s } \varphi + \dot { y } \operatorname { s i n } \varphi ) , } \\
{ \ddot { y } = - 2 \omega \dot { x } \operatorname { s i n } \varphi , } \\
{ \ddot { z } = - g - 2 \omega \dot { x } \operatorname { c o s } \varphi , }
\end{array} \text { при начальных условиях } \left\{\begin{array}{l}
t=0, \\
x(0)=0, \dot{x}(0)=u, \\
y(0)=0, \dot{y}(0)=v, \\
z(0)=0, \dot{z}(0)=w,
\end{array}\right.\right.
$$

где угол $\varphi$ - географическая широта в данной точке земной поверхности, 